\title{
LEXICON ICONOGRAPHICUM MYTHOLOGIAE CLASSICAE
} II, Aphrodisias-Athena 2 vols. in - 40, encadernado. Vol. 1: texto, XXII 1112 págs. . vol. 2: pranchas, 904 págs. com 815 pranchas. Artemis Verlag, Zurique/Munique, 1984.

\section{Res. por Haiganuch Sarian, MAE/USP}

Em 1981 fol pubficado o tomo I do Lexicon Iconographicum Mythologiae Classicae (LIMC); o tomo II é editado em 1984, conforme um programa rigoroso de produção cientfica, organizaçăo $\theta$ administraçăo das equipes de pesquisa em nivel internacional. Ritmo e resultado surpreendentes, para náo dizer mesmo miraculosos, que devemos atribuir ao trabalho, inteligência, competência e dedicaçăo de Lilly Kahil. Se o tomo I fol alvo de comentário e análises favoráveis por parte de especialistas dentre os melhores da atualidade, com muito mais razáo se festejou o LIMC 11 . O primeiro da série abrange os artigos Aara - Aphlad e destaca, seguindo a ordem alfabética dos nomes mitologicos adotada pela obra, figuras que com raras exceçరీes năo se situam dentre as mais importantes do panteáo clássico. Privilegia, por certo, a Iconografla heroica, por exemplo, referente a Achilleus e Agamemnon ou, entăo, as Amazones (ver noticia por nós publicada em Humanitas, XXXV - XXXVI, Coimbra, 1984, págs. 441-443); entretanto, por coincidência e decorrência dessa mesma ordem alfabética, 0 tomo II oferece espaço para as grandes divindades da mitologia clássica. De um total de 114 artigos, menos numeroso portanto o LIMC I, apresenta algumas nubricas que equivalem a verdadeiras monografias, tal $\theta$ a importåncia $\theta$ a extensáo da documentação imagética dessas divindades. Assim é que, num só tomo, dispomos da iconografia de deuses do porte de Afrodite, Apolo, Ares, Ártemis, Asclëpio e Atena.

Às qualidades próprias do tomo I soma-se a exceléncia do tomo II, confirmando desse modo que essa obra preenche, de longe, a lacuna na bibliografia clentfica sobre o assunto, e que ela chegará ao término (tomo VII/Zeus) cumprindo o padrăo do mais alto nivel.

No seu aspecto material, ressalta-se a perfeiçăo da impressăo e da llustraçấo. 0 texto se apresenta em duas colunas, as imagens ora sáo desenhos inseridos no volume de texto, ora são fotografias impressas no volume de pranchas. Todas as ilustraçర̋es săo em branco e preto, com uma rara exceçáo neste tomo II, onde o frontisplcio em cores reproduz excepcional mosaico descoberto em 1982 na Jordânia e datado de meados do séc. VI d.C., com as figuras de Afrodite, Adonis, Cárites e Erotes, todas elas identificadas com inscriçర̋es gregas. Os artigos săo redigidos nas quatro línguas modernas consideradas de conhecimento fundamental entre os estudiosos da Antiguldade Clássica, francês, inglês, italiano $\theta$ alemão, à escolha dos autores, que somam a 66 especialistas originários de uns quinze palses de todas as partes.

O caráter intemacional dessa obra não transparece apenas no elenco de palses representados entre os autores. Todo o programa do LIMC, desde o levantamento da documentaçăo iconográfica clássica (grega, etrusca e romana), conservada em todos 
os museus e coleços particulares do mundo ate o seu controle cientffico, depende de uma verdadeira organizaçăo internacional, cujo funcionamento e atribuiçరes são indicados nas páginas introdutórias (V-XII). Há que destacar, em primeiro ugar, 0 alto patrocinio de entidades cientfico-culturais européias como a Union Académique Internationale (Bruxelas), Consell International de la Philosophie et des Sciences Humaines (Paris), Association Internationale doÉtudes du Sud-Est Européen (Bucareste), Unesco (Paris) e Commission Internationale de Numismmatique (filiada ao Comité International de Sciences Historiques - CISH). Acrescenta-se o apoio financeiro de vinte e tres instituiçoes academicas e outras, pertencentes a 16 palses reunidos em tomo do Consell de Fondation, sediado em Basilela e cujo Presidente, Nikolaos Yalouris, 60 autor do prefácio (p. VII) no qual ressalta o apoio moral $\theta$ financeiro dos diversos palses, incluindo a Grécla, através náo só de seu governo e instituiçóes como também de doadores particulares, auxllio indispensável "pour Pavancement des études classiques et par là mème pour thumanisme en générar".

Devemos privilegiar também o Comité de Rédaction composto de especialistas dentre os methores em iconografia clássica, e que náo funciona em absoluto como mero quadro honorffico, mas que interfere efetivamente, quando necessário, no trabalho dos autores: J.-Ch. Balty (Bruxelas), J. Boardman (Oxford), Ph. Bruneau (Paris), F. Canciani (Roma), L. Kahil (Paris/Friburgo), V. Lambrinoudakis (Atenas), E. Simon (Heidelberg).

No "avant-propos" (pågs. VIII-XII), Lilly Kahil, Secretária Geral do LIMC, particulaniza a composição dessa organizaçăo internacional que inclui ainda um Comité Scientifique composto de estudiosos de 34 paises, incluindo o Brasil, e, por fim, discrimina 0 funcionamento administrativo $\theta$ técnico, documental $\theta$ arquivistico do programa distribuldo em três centros, Paris, Heidelberg e Basiléia, situando-se nessa cidade a Rédaction Centrale do LIMC cujo sucesso, disciplina, excelência cientffica e técnica devem multo aos arqueólogos e filólogos sulços e alemăes.

Além de uma organizaçăo internacional sólida e de uma administração eficiente, 0 programa do LIMC tem atuado com base numa orientaçăo cientffica, institulda, aperfeiçoada e divulgada entre os autores desde o infcio de suas atividades em 1973. Para tanto, alem de freqüentes reunibes do Comité de Rédaction $\theta$ das reunibes bienais do Comité Scientifique International, foram publicados alguns boletins contendo instruçסes e normas a serem seguidas pelos pesquisadores encarregados da elaboraçăo dos artigos. Um destés boletins, publicado na sua última ediçáo em 1981 e regularmente atuaIzado atraves de folhas avulsas de suplemento, reúne as abreviaçós bibliográficas de que se servem os autores:LIMC, Abréviations, Artemis Verlag, Zurique/Munique, 1981, págs. 1-40, comodamente reproduzidas nas páginas introdutórias do LIMC I, 1 e acrescidas de um Suplemento nas págs. XV-XVIV do LIMC II, 1. Essas abreviaçరes concernem todo tipo de referéncia bibliográfica incluindo ediçoes das fontes escritas e àqueologlcas cujas simples enumeraçăo permite avaliar a rigorosa erudiçăo indispensável a esse tipo de pesquisa e que permela passo a passo os inúmeros artigos do Lexicon A. Abrevlaçoes dos repertórios de textos antigos (fragmentos, inscriçoes, 
papiros, léxicos, etc.), de autores gregos e latinos; B. Abreviaçסes de revistas e periodicos num total de 368 thulos; C. Abreviaçbes de obras, com especial atençăo à publtcaçăo sistemática das fontes da cultura material, mas também incluindo outros estudos sobre a mitologia, religiáo e arte do mundo antigo.

O rigor na indicaçăo das referências de fontes textuais e bibliografia acompanha também a publicaçăo do elenco das ilustraçoes no volume de texto, com a citaçăo das obras de que foram extraldas (págs. XVIII-XXII)e, no volume de pranchas (págs. 816-904), um (ndice relaciona todas as fotografias publicadas com a mençáo dos locais em que os objetos estão conservados (museus, coleçరes, stitios arqueologicos, etc.), bem como a origem das fotografias seguidas do seu número de classificaçấo.

Normas tamberm foram in stituldas no tocante à estrutura dos artigos, a qual parte de alguns pressupostos metologicos claros concernentes aos objetivos da obra divut gados em inúmeras revistas, col6quios, congressos e registrados no texto introdutório de Lilly Kahil do LIMC I do qual ressaltamos o essencial em nossa resenha acima citada, escrevendo à pág. 441: "O objetivo desta obra é de sistematizar os nossos conhecimentos na área da iconografia mitológica clássica, nos limites cronológicos situados entre 0 final do perfodo micênico $\theta 0$ início do perlodo paleocristão. Obra ínovadora, compreende năo apenas a iconografia grega, etrusca e romana, mas também a iconografia periférica, isto $\theta$, das regibes helenizadas ou romanizadas. Acentua essencialmente 0 estudo das imagens e de sua evoluçăo, com base em todo o tipo de documentos figurativos, esculturas e relevos, vasos pintados, mosaicos, moedas, etc. Recorre com freqüência às fontes escritas referentes às representaçסes imagéticas dos mitos. Desse modo, é uma obra que interessa aos especialistas da Antiguidade Clássica, incluindo arqueólogos, filologos, historiadores, historiadores da arte, filosofos, historiadores da religlăo; interessa tambem a todas as pesquisas que valorizam a imagem como forma de expressăo no decorrer dos tempos, até a época contemporânea".

Dentro desta perspectiva e para atingiri seus objetivos, foram publicados outros boletins contendo orientaçoes aos autores, o primeiro deles $\theta$, sem dúvida, 0 mais Importante, datado dos inicios do programa: LIMC. Directives aux auteurs / Articles modeles. Artemis Verlag, Zurique/Munique, págs. 3-20, 2 pranchas, contendo o principal da metodologia desse Lexicon, igualmente reproduzida nas páginas introdutórias do LIMC I (cf. págs. XV-XXX longo texto de Lilly Kahil, repetido nas quatro linguas adotadas pelo LIMC). Vale a pena determo-nos na exposiçăo da estrutura dos artigos, conforme as normas estabelecidas para o LIMC, como preâmbulo ao comentárb que se seguirá a respelto dos mais importantes verbetes publicados no LIMC II.

Os artigos, que em muitos casos săo verdadeiras monografias ou livros pela sua extensáo, dividem-se em quatro partes: I. Introduçáo, II. Bibliografia, III. Catálogo IV. Comentário.

1. Introduçăa Comporta a indicaçăo dos nomes da figura mitológica, em grego, etrusco e latim, incluindo todas as formas existentes (por exemplo, no Unear B micentco, se for o caso, nas inscriçбes, etc.); nos casos de sincretismos, assimilaçбes ou 
identificaçós regionals nas áreas periféricas ao mundo clássico, as denominaçరos sáo indicadas onde há o tratamento especffico dessas entidades ou heróis. Seguem-se a definiçáo da figura mitologica $\theta$ a descriçăo dos temas com elas relacionados, bem como a mençăo das principais referências literárias quando essas sáo importantes para o estudo iconográfico.

II. Bibliografia. Trata-se apenas da bibliografia geral sobre a figura mitológica ou estudos de histónia da religiăo e de mitologia em que essas figuras recebem uma abordagem particulanizada. Todas as obras de referência aos objetos são citados no Catálogo ou no Comentária.

III. Catáloga. Propbo-se logo no infcio um plano desse catálogo com suas várias divisós e subdivisóes. O catálogo propriamente dito é uma parte substanciosa do artigo, $\theta$ apesar de ser estabelecido com rigor năo se pretende que seja exaustivo. É portanto seletivo desde que se indiquem todos os tipos iconográficos e suas variantes, bem como todas as categorias de objetos que representam as figuras mitológicas. A descrição dos objetos nos catálogos segue nomas estritas que uniformizam os vários artigos do LIMC, funcionando como uma publicaçăo sistemática dos objetos enquanto suportes ou expressóes de imagens. Nesse sentido, ela $\theta$ vista de um ângulo estritamente iconogrăfico. Săo portanto indicados: a) o tipo de objeto, forma e lugar de fabricaçáo; b) as referências museográficas; c) o local de achado; d) uma bibliografia seletiva, com as obras básicas de referência, o estudo mais recente e melhor documentado e também a melhor ilustraçăo; e) a cronologia e o nome do seu proponente; f) a descriçăo compreendendo apenas a indicaçăo das figuras mitológicas representadas, seguida de sua açáo e particularizando a figura principal tratada no artigo.

IV. Comentário. Năo segue normas tăo estritas quanto o catálogo me.s de uma maneira geral pretende-se que seja essencialmente iconográfico e fundamentado nos documentos m:encionados no catálogo. Nesse, os objetos seguem uma ordem iconográfica, considerando sucessivamente os episódios da vida do personagem mitológico em questão; o comentário segue a ordem cronológica dos objetos tomados como documentos que transmitem a imagem. Assim, apesar de inúmeras variaçరes no tratamento dessa parte do artigo, são comuns os seguintes itens: a) indicação do surgimento das primeiras representaçбes da figura mitológica; b) tanto quanto possivel mostram-se as relaçóes entre a imagem e a tradiçấo literária ou entre a imagem e a prática cultual, mas tomando a imagem como ponto de partida e utilizando tradiçáo literária ou prática cultual apenas para reforçar a compreensáo do desenvolvimento iconográfico; c) ressalta-se a diferença dos temas iconográficos na área grega, etrusca $\theta$ romana, ou ao contrário sua convergência; d) finalmente, pode-se evocar a repartiçăo geográfica dos temas iconográficos e colocá-los em relaçăo com a distribuiçăo espacial dos santuários, ou cultos, ligados aos mesmos personagens divinos ou heróicos.

Essas normas caracterizam no geral todos os artigos do LIMC, hevendo, entretanto, aqui e ali algumas modificaçס̋es, adaptaçర̃es ou mesmo inovaçס̄es dependendo de exigências às vezes do próprio tema abordado outras vezes da orientaçăo intelectual do autor. À parte essas ressalvas, os princlpios que preconizam a estrutura dos ar- 
tıgos são respeitados land omo resultado uma obra nomogênea. de fácıl leitura $t$ :ompreensão

Jiffcil seria resenhar todos os artigos do L.IMC " Assim sendo e para fazer justiça aos temas mais importantes. lulgamos necessáno destacar as figuras mitológicas mais significativas no plano do panteão clássıco e da ıconografia: năo há dúvida de que merecem relevo os artigos sobre tres grandes divindades femininas Aphrodite, Artemis, Athena e duas divindades masculinas situadas também entre as maiores - Apollor, Ares. Algumas subdivisరes foram adotadas para o tratamento das diversas formas regionais desses deuses, conforme as normas gerais que regem o Lexicon, isto $\theta$, a documentaçăo grega seguida da etrusca e da romana; a iconografia das regióes periféricas do mundo oriental tratada logo depois da parte grega; das regiðes ocidentais, depois da parte romana.

Essas subdivisర̋es, cobrindo áreas especfficas do saber arqueológico e histórico, exigiriam a colaboração de diferentes autores, abrindo ainda mais o leque da participação internacional. Convém lembrar que a iconografia mitológica das áreas periféricas da cultura grega, etrusca e romana, bem como as questóes referentes à projeçáo da imagem grega em outros contextos, como o mundo etrusco e romano, inspirou, como preparaçăo, questionamento e reflexăo ao programa do LIMC, dois colóquios internacionais realizados em Paris, resultando nas duas publicaçర̋es cuja complementaridade ao Lexicon $\&$ indiscuttvel Kahil. Augé, ihr , dir... Mythologie Gréco-Romaine, Mythologies Périphériques. Études d'Iconographie Éditions du Centre National de la Rechercche Scientifique. Paris. 1981 Kahil L Augé. Chr. Linant de Bellefonds, P., (dir.), Iconographie Classique et Identités Régionales. Bulletin de Correspondance Helléniqua Supplément XIV. Diffusion De Boccard, Paris, 1986.

Deixando o artigo Aphrodite para um comentánio a ser feito logo em seguida, destaquemos por exemplo que Apollon é acompanhado do verbete Aplu (iconografia etrusca) e Apollo (iconografia romana); Artemis se subdivide em pequenas entidades bcais da Ásia Menor (como Artemis/Anantise e a expressiva Artemis Ephesia para ser tratada depois como Artumes (no mundo etrusco) e Diana (no mundo romano); do mesmo modo, Athena se desenvolve em Athena/Menerva (representaçठes etruscas) $\theta$ Athena/Minerva (identificaçăo romana), com importante texto sobre a lconografia de Minerva na África e na Gália: Ares se subdivide principalmente em Laran (Etrúria) e Mars (Roma)

Além dessas grandes divindades. alguns verbetes do LIMC II săo dedicados a figuras menos expressivas ıconograficamente Mas de porte médio, merecem destaque Asklépios. Astyanax e Atalanta, todos os três substanciosos estudos. Náo passaram desapercebidas entidades nitológicas ou alegorias que tiveram rara expressáo imagética: por exemplo. Arete. alegoria do valor militar e moral, $\theta$ figurada em apenas quatro documentos Arish, deus púnico da guerra, é representado só uma vez.

Se a estrutura dos artigos obedece, de modo geral, a um programa definido, no conteúdo as variaçớes săo mais freqüentes. Com exceçăo do catálogo, onde predomina uma linguagem resumida ao essencial $\theta$ acompanhada de abreviaçరes, sinais gráfi- 
$\cos \theta$ pontuaçåo de acordo com as nomas pré-estabelecidas, outros capftulos săo tratados com mais flexibildade, o que aliás, nâo pertuba o conjunto da obra. Sem contar particularidades lingülsticas, graças à utilizaçáo de quatro linguas diferentes, a orientaçáo cientfica dos autores $\theta$ suas preocupaçoes intelectuais interferem também no tratamento ora da introduçáo ora da bibliografia ora do comentária. Nesta parte. principalmente, pode-se verificar que há um equilbrio refletindo ao mesmo tempo um conhecimento em iconografia/história da arte/ prática cultual como transparece no artigo Arthemis (Lilly Kahil). Entretanto esse equilbrio năo é percebido em artigos como Athena (P. Demargne) omde aspectos de história da religiáo parecem se sobrepor demasiadamente à expressáo art́stica e imagética dessa deusa; do mesmo modo, no estudo sobre Asklepios (B. Holtzmann) $\theta 0$ historiador da arte que abafa 0 estudioso da lconografia; situaçăo oposta se vê em Ares (Ph. Bruneau) onde a análise da imaglstica e as questoes que dela decorrem săo essenciais e assumem toda a sua importâncla.

No que concerne Aphrodite, náo podemos deixar de nos surpreender com a niqueza da documentaçăo iconográfica, biblográfica e textual. Seu principal autor, para a parte grega, A. Delivorias, teve a colaboraçáo de G. Berger-Doer e A. Kossatz-Deissmann. $O$ texto $\Theta$ bongo, compreendendo 174 páginas em duas colunas, 170 páginas de pranchas e 1570 números no catálogo referentes apenas a Afrodíte grega. Entretanto náo se apresentou o comentário como captulo à parte; os autores preferiram inserir pequenos textos introduzindo séries de tipos iconográficos no interior do próprio catálogo. Por outro lado, após o estudo da Afrodite grega, esperava-se a iconografia de Venus, o que estarla conforme as regras do LIMC, mas ela é curiosamente remetida à pág. 176 para o LIMC III, Addenda

Apesar desses deslizes de carácter estrutural, a substâncla é notável. Såo muitas as subdivisós de acordo com as várlas denominaçoes regionais. Assim sendo, temos as págs. 151-154 Aphrodite/Aphrodisias, hipostase local da deusa em Afrodisias da Cária, tratada por R. Fleischer e, do mesmo autor, Aphroditai Kastnietides, também denominaçåo local da deusa em Aspendos da Panflia. M.-O. Jentel apresenta um texto multo significativo sobre Aphrodite (in Peripheria Orientali) as págs. 154-166, com 246 números no catálogo, deixando para F. Zayadine o estudo particular de APUzza a deusa árabe assinilada a Atrodite na Nabatéla. Finalmente, essa rubrica sobre a lconografia de Afrodite $\theta$ suas identificaçбos religionais termina com a primorosa participaçáo de R. Bloch (e a colaboraçáo de N. Minot) que trata de Turan, a Afrodite no mundo etrusco.

Os documentos publicados săo de grande parte inéditos ou pouco conhecidos ou mesmo de diffill acesso. Reunidos como estáo nesses dols volumes (texto e pranchas), permitem um estudo comparativo que nâo deixa de ter sua importancia, năo só no interior de um mesmo artigo como tambem de um verbete o outro. Vale lembrar as interessantes aproximaçסos possivets entre representaçסes aniconicas e expressőes hermaicas de divindades, sem contar os vários xoana formas primitivas das figu- 
raçбes divinas, para citar apenas alguns exemplos. Uma reuniăo de tal porte, destacando as vánias categorias de objetos, permite uma compreensáo melhor das representaçס̋es em suportes de natureza e funçáo bastante diferenciadas, de modo a captar em profundidade o significado dessas imagens também em contextos diferentes: uma imagem nåo evoluirá do mesmo modo na dintura cerâmica, na estatuária, nos mosaicos, nas moedas. Só um levantamento táo rigoroso da iconografia mitológica clássica pode permitir a abertura para novas orientaçбes de estudo e de interpretaçáo nessa área. Além do seu valor inestimável como tesouro documental, essa obra permanecerá como uma referência indispensável ao progresso do conhecimento sobre as mais significativas formas de expressåo da cultura e da mentalidade no mundo antigo: arte, imagem, mito e religiăo. 